\title{
Pengaruh High Pressure Kompresor Terhadap Performansi Sistem Refrigerasi Dengan Menggunakan R-134a Dan Refrigeran Hidrokarbon
}

\author{
${ }^{1}$ Puji Saksono, ${ }^{2}$ Budha Maryanti \\ Program Studi Teknik Mesin Fakultas Teknologi Industri Universitas Balikpapan \\ Jl. Pupuk Raya PO BOX 335 Balikpapan. Telp./Fax. 0542-764205 \\ Email : saksono_puji@yahoo.co.id; budha_maryanti@yahoo.com
}

\begin{abstract}
This general refrigeration system is used to conserve food and refreshing of air. The useful of refrigeration system depends of maximal performance this from main component as compressor, condensor, expantion device and evaporation. This research aims to know how the big high pressure compressor to its value performance. The examination is conducted by using appliance test system of refrigeration system which has been modified with the equipments of control. The refrigerant used of two variant different ( $R-134 a$ and hidrocarbon refrigerant). Result of research shows that high pressure or compressor discharge from both refrigerant variant of different, the influence for value of COP (coeffcient of performance), and the economical of electric energy comsumption.
\end{abstract}

Keywords: refrigerant variant, high pressure compressor, COP.

\begin{abstract}
Abstrak
Pada umumnya sistem refrigerasi digunakan untuk mengawetkan makanan dan penyegaran udara. Pemanfaatan sistem refrigerasi sangat tergantung dari kinerja maksimal komponen utamanya seperti kompresor, kondensor, alat ekspansi dan evaporator. Penelitian ini bertujuan untuk mengetahui seberapa besar pengaruh high pressure kompresor terhadap nilai performansinya. Pengujian dilakukan dengan menggunakan alat uji dari sistem refrigerasi yang telah dimodifikasi dengan peralatan kontrol. Adapun refrigeran yang digunakan yaitu dua jenis yang berbeda $(R-134 a$ dan refrigeran hidrokarbon). Hasil penelitian menunjukan bahwa nilai high pressure atau discharge kompresor dari kedua jenis refrigran tersebut berbeda, yang tentunya akan mempengaruhi nilai COP (coeffcient of performance) dan penghematan komsumsi energi listrik.
\end{abstract}

Kata kunci: Jenis refrigeran, high pressuret kompresor, COP.

\section{Pendahuluan}

Sistem refrigerasi dan pengkondisian udara banyak digunakan di dunia industri makanan, tranportasi, kesehatan maupun rumah tangga. Refrigeran yang umum dipakai pada saat ini mengandung senyawa sintetik HCFC (Hydrochlorofluorocarbon) seperti R-22, senyawa CFC (Chlorofluorocarbon) seperti R-12 dan HFC (Hidrofluorocacbon) seperti R134a yang memiliki sifat-sifat yang baik ditinjau dari segi teknik seperti: kestabilan yang tinggi, tidak mudah terbakar, tidak beracun dan relatif mudah didapat.

Refrigeran HFC walaupun tidak mempunyai unsur chlor yang dapat merusak lapisan ozon tetapi mengandung unsur fluor yang dapat menimbulkan pemanasan global (Global Warming Potential/GWP) apabila refrigeran tersebut terlepas ke atmospher.

Pemakaian hidrokarbon sebagai refrigeran pengganti merupakan salah 
satu alternatif solusi untuk mengatasi masalah ini, karena refrigeran hidrokarbon tidak mempunyai efek negatif terhadap lingkungan.

Dengan demikian retrofit merupakan penggantian refrigeran yang lebih ramah lingkungan, di samping kelebihan lainnya yaitu dengan retrofit secara teoritis dan dapat dibuktikan secara eksperimen akan menghasilkan nilai COP (coeffcient of performance) yang lebih tinggi, sehingga efisiensi dari sistem refrigerasi akan semakin lebih baik.

Pemanfaatan sistem refrigerasi sangat tergantung dari kinerja maksimal komponen utamanya seperti kompresor, kondensor, alat ekspansi dan evaporator.

Adapun rumusan masalah dalam penelitian ini adalah seberapa besar pengaruh high pressure kompresor terhadap performansi sistem refrigerasi dengan menggunakan R-134a dan hidrokarbon ?

Penelitian ini bertujuan untuk mengetahui perbandingan dari pengaruh high pressure kompresor terhadap performansi sistem refrigerasi sehingga proses retrofit dari R-134a ke refrigeran hidrokarbon dapat dilakukan. Sedangkan manfaat penelitian sebagai media karya ilmiah bagi peneliti untuk dapat mengembangkan keilmuannya di bidang teknik refrigerasi.

\section{Metode Penelitian}

\subsection{Waktu dan Tempat Penelitian}

Penelitian dilakukan pada bulan Januari s/d Juni 2014 di laboratorium mesin pendingin program studi Teknik Mesin Fakultas Teknologi Industri Universitas Balikpapan.

\subsection{Bahan dan Alat}

Adapun perlengkapan dan alat penelitian yang digunakan adalah:

1. Satu unit alat uji sistim refrigrasi yang sudah dimodifikasi dengan menambahkan perangkat alat ukur (pressure and temperature gauge)

2. Pompa vakum
3. Gauge manifold

4. Termometer (digital)

5. Timbangan refrigeran (digital)

6. Refrigeran R-134a merk Klea dan hidrokarbon merk Mesicool (MC134) produksi Pertamina

7. Leak detector (alat uji kebocoran refrigeran)

8. Multimeter (Gigital)

9. Peralatan workshop

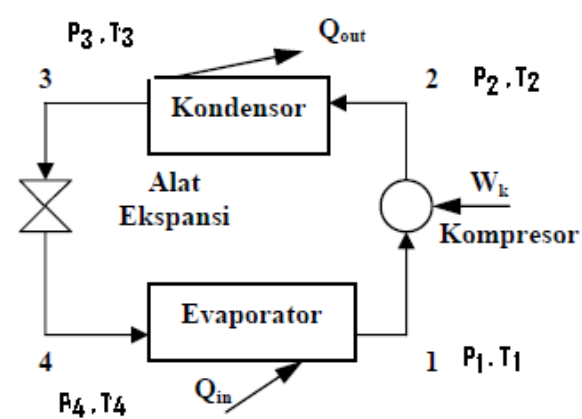

Gambar 1 Skema unit alat uji sistem refrigerasi

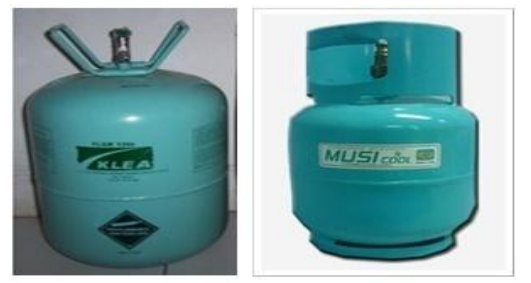

Gambar 2. Refrigeran R-134a dan hidrokarbon MC-134

\subsection{Langkah-langkah Penelitian}

Langkah-langkah penelitian yang dilakukan sebagai berikut:

1. Menyiapkan peralatan uji sistim refrigerasi dan perlengkapan lainnya

2. Sistim divakum terlebih dahulu dengan menggunakan pompa vakum

3. Melakukan pengisian refrigeran R134a sampai isian penuh

4. Menghidupkan alat uji sampai dengan kondisi steady state.

5. Mencatat hasil pengukuran $\mathrm{T}_{1}, \mathrm{~T}_{2}, \mathrm{~T}_{3}$, $\mathrm{T}_{4}, \mathrm{P}_{1}, \mathrm{P}_{2}$

6. Mengulang semua langkah dengan menggunakan refrigeran MC-134. 
2.4. Variabel Penelitian

Variabel dalam penelitian:

1. Variabel bebas, yang meliputi:

- Jenis Refrigran (R-134a dan Hidrokarbon MC-134)

- High pressure (Psi)

- Interval waktu (menit).

2. Variabel terikat, yang meliputi:

- Kerja Kompresi [kJ/kg]

- Efek Refrigerasi [kJ/kg]

- Kuat arus [Ampere]

- COP (coeffcient of performance)

3. Variabel Kontrol, yang meliputi:

- Temperatur ruang uji $28-30{ }^{0} \mathrm{C}$.

\section{Hasil dan Pembahasan}

\subsection{Spesifikasi Alat Uji}

Unit alat uji yang digunakan dalam pengujian adalah freezer merek
Sanyo yang telah ditambah dengan alat ukur pressure dan temperature dengan data:

1. Type Kompressor: Reciprocating /

$$
\text { Piston }
$$

2. Model Kompressor : Model

$$
\text { Terbuka }
$$

3. Jenis Kompressor : Hermatik

4. Daya Kompressor : $1 / 3 \mathrm{PK}$

5. Rated Current : $0,5 \mathrm{~A}-0,9 \mathrm{~A}$ ( 220V).

Data diperoleh dari pengujian langsung pada saat freezer beroperasi (running) dengan mode high pada switch yang terdapat pada freezer.

\subsection{Data hasil pengujian siklus ideal}

Tabel 1. Data hasil pengujian dengan menggunakan refrigeran R-134a

\begin{tabular}{|c|c|c|c|c|c|c|c|c|}
\hline No. & $\begin{array}{c}\text { Menit } \\
\text { ke- }\end{array}$ & $\begin{array}{c}\mathrm{P}_{1} \text { (Low } \\
\text { pressure) } \\
{[\text { Psi }]}\end{array}$ & $\begin{array}{c}\mathrm{P}_{2} \text { (High } \\
\text { pressure) } \\
{[\text { Psi }]}\end{array}$ & $\begin{array}{c}\mathrm{T}_{1} \\
{\left[{ }^{\circ} \mathrm{C}\right]}\end{array}$ & $\begin{array}{c}\mathrm{T}_{2} \\
{\left[{ }^{\circ} \mathrm{C}\right]}\end{array}$ & $\begin{array}{c}\mathrm{T}_{3} \\
{\left[{ }^{\circ} \mathrm{C}\right]}\end{array}$ & $\begin{array}{c}\mathrm{T}_{4} \\
{\left[{ }^{\circ} \mathrm{C}\right]}\end{array}$ & $\begin{array}{c}\text { Kuat } \\
\text { Arus } \\
{[\text { Ampere }]}\end{array}$ \\
\hline 1 & 10 & 15 & 188 & 22 & 60 & 37 & -10 & 0,99 \\
\hline 2 & 20 & 8 & 180 & 20 & 63 & 36 & -16 & 0,97 \\
\hline 3 & 30 & 5 & 170 & 19 & 65 & 35 & -19 & 0,95 \\
\hline 4 & 40 & 4 & 160 & 17 & 67 & 35 & -23 & 0,94 \\
\hline 5 & 50 & 3 & 150 & 15 & 70 & 34 & -25 & 0,93 \\
\hline
\end{tabular}

Tabel 2. Data hasil pengujian dengan menggunakan refrigeran hidrokarbon MC-134

\begin{tabular}{|c|c|c|c|c|c|c|c|c|}
\hline No. & $\begin{array}{c}\text { Menit } \\
\text { ke- }\end{array}$ & $\begin{array}{c}\mathrm{P}_{1} \text { (Low } \\
\text { pressure) } \\
{[\text { Psi] }}\end{array}$ & $\begin{array}{c}\mathrm{P}_{2} \text { (High } \\
\text { pressure) } \\
{[\text { Psi] }}\end{array}$ & $\begin{array}{c}\mathrm{T}_{1} \\
{\left[{ }^{\circ} \mathrm{C}\right]}\end{array}$ & $\begin{array}{c}\mathrm{T}_{2} \\
{\left[{ }^{\circ} \mathrm{C}\right]}\end{array}$ & $\begin{array}{c}\mathrm{T}_{3} \\
{\left[{ }^{\circ} \mathrm{C}\right]}\end{array}$ & $\begin{array}{c}\mathrm{T}_{4} \\
{\left[{ }^{\circ} \mathrm{C}\right]}\end{array}$ & $\begin{array}{c}\text { Kuat } \\
\text { Arus } \\
{[\text { Ampere }]}\end{array}$ \\
\hline 1 & 10 & 15 & 170 & 20,0 & 60,0 & 34,0 & $-15,6$ & 0,92 \\
\hline 2 & 20 & 10 & 168 & 19,3 & 61,2 & 33,6 & $-18,8$ & 0,88 \\
\hline 3 & 30 & 5 & 166 & 19,0 & 64,0 & 33,1 & $-21,4$ & 0,87 \\
\hline 4 & 40 & 4 & 164 & 18,4 & 64,4 & 32,3 & $-26,5$ & 0,85 \\
\hline 5 & 50 & 3 & 160 & 17,2 & 65,0 & 32,0 & $-34,2$ & 0,84 \\
\hline
\end{tabular}


Dengan menggunakan tabel sifat-sifat cairan dan uap jenuh refrigerant R-134a dan MC134 didapatkan:

Tabel 3. Hasil pengolahan data dengan refrigeran R-134a.

\begin{tabular}{|c|c|c|c|c|c|c|c|}
\hline \multirow{2}{*}{ No. } & \multicolumn{3}{|c|}{ Enthalpy (kJ/kg) } & \multirow{2}{*}{$\begin{array}{c}\mathrm{w}=\text { Kerja } \\
\text { Kompresi } \\
\mathrm{h}_{2}-\mathrm{h}_{1} \\
{[\mathrm{~kJ} / \mathrm{kg}]}\end{array}$} & \multirow{2}{*}{$\begin{array}{c}\mathrm{q}_{\mathrm{rc}}=\text { Efek } \\
\text { Refrigerasi } \\
\mathrm{h}_{1-\mathrm{h}_{4}} \\
{[\mathrm{~kJ} / \mathrm{kg}]}\end{array}$} & \multirow{2}{*}{$\begin{array}{c}\mathrm{q}_{\mathrm{rj}}=\text { Kalor } \\
\text { keluar } \\
\text { Kondensor } \\
\mathrm{h}_{2}-\mathrm{h}_{3} \\
{[\mathrm{~kJ} / \mathrm{kg}]}\end{array}$} & \multirow{2}{*}{$\begin{array}{c}\mathrm{COP}= \\
\left(\mathrm{h}_{1}-\mathrm{h}_{4}\right) / \\
\left(\mathrm{h}_{2}-\mathrm{h}_{1}\right)\end{array}$} \\
\hline & $\mathrm{h}_{1}$ & $\mathrm{~h}_{2}$ & $\mathrm{~h}_{3}=\mathrm{h}_{4}$ & & & & \\
\hline 1 & 361,321 & 423,184 & 226,697 & 61,863 & 134,624 & 196,487 & 2,17 \\
\hline 2 & 357,920 & 423,667 & 225,036 & 65,747 & 132,884 & 198,631 & 2,02 \\
\hline 3 & 355,889 & 424,255 & 223,748 & 68,366 & 132,141 & 200,507 & 1,93 \\
\hline 4 & 350,457 & 425,824 & 221,984 & 75,367 & 128,473 & 203,840 & 1,70 \\
\hline 5 & 347,866 & 427,862 & 219,281 & 79,996 & 128,595 & 208,581 & 1,61 \\
\hline
\end{tabular}

Tabel 4. Hasil pengolahan data dengan refrigeran hidrokarbon MC-134

\begin{tabular}{|c|c|c|c|c|c|c|c|}
\hline \multirow{2}{*}{ No. } & \multicolumn{3}{|c|}{ Enthalpy (kJ/kg) } & \multirow{2}{*}{$\begin{array}{c}\mathrm{w}=\text { Kerja } \\
\text { Kompresi } \\
\mathrm{h}_{2} \mathrm{~h}_{1} \\
{[\mathrm{~kJ} / \mathrm{kg}]}\end{array}$} & \multirow{2}{*}{$\begin{array}{c}\mathrm{q}_{\mathrm{rc}}=\text { Efek } \\
\text { Refrigerasi } \\
\mathrm{h}_{1-\mathrm{h}_{4}} \\
{[\mathrm{~kJ} / \mathrm{kg}]}\end{array}$} & \multirow{2}{*}{$\begin{array}{c}\mathrm{q}_{\mathrm{rj}}=\text { Kalor } \\
\text { keluar } \\
\text { Kondensor } \\
\mathrm{h}_{2} \cdot \mathrm{h}_{3} \\
{[\mathrm{~kJ} / \mathrm{kg}]}\end{array}$} & \multirow{2}{*}{$\begin{array}{c}\mathrm{COP}= \\
\left(\mathrm{h}_{1}-\mathrm{h}_{4}\right) / \\
\left(\mathrm{h}_{2}-\mathrm{h}_{1}\right)\end{array}$} \\
\hline & $\mathrm{h}_{1}$ & $\mathrm{~h}_{2}$ & $\mathrm{~h}_{3}=\mathrm{h}_{4}$ & & & & \\
\hline 1 & 552,470 & 642,740 & 286,440 & 90,270 & 266,030 & 356,300 & 2,94 \\
\hline 2 & 549,110 & 643,810 & 285,260 & 94,700 & 263,850 & 358,560 & 2,79 \\
\hline 3 & 544,760 & 646,620 & 284,120 & 101,860 & 260,640 & 362,500 & 2,56 \\
\hline 4 & 538,280 & 646,940 & 281,980 & 108,660 & 256,30 & 364,960 & 2,36 \\
\hline 5 & 528,040 & 647,580 & 281,120 & 119,540 & 246,920 & 366,460 & 2,06 \\
\hline
\end{tabular}

\subsection{Pembahasan}

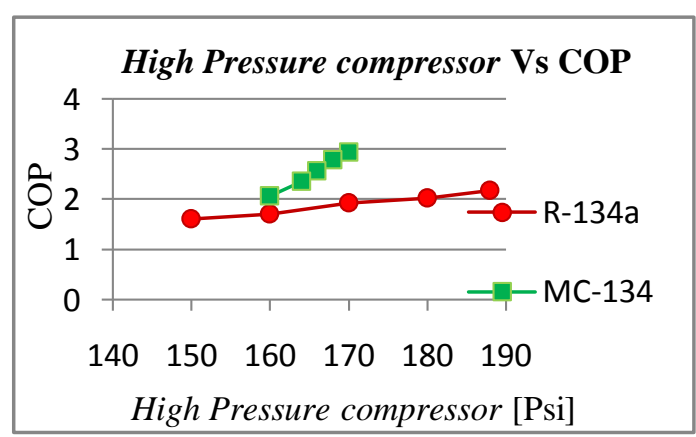

Gambar 1. Grafik perbandingan High Pressure compressor terhadap Nilai COP
Berdasarkan gambar grafik di atas dapat disimpulkan bahwa kenaikan high pressure compressor setelah melewati kompresor pada kedua jenis refrigeran berbanding lurus terhadap kenaikan nilai Coefisien of Performance (COP).

Nilai COP yang paling tinggi menggunakan refrigeran hidrokarbon sebesar 2,94 pada saat high pressure compressor sebesar 170 Psi. Sedangkan dengan menggunaan R-134a hanya sebesar 2,17 walaupun 
high pressure compressor sebesar 188 Psi.

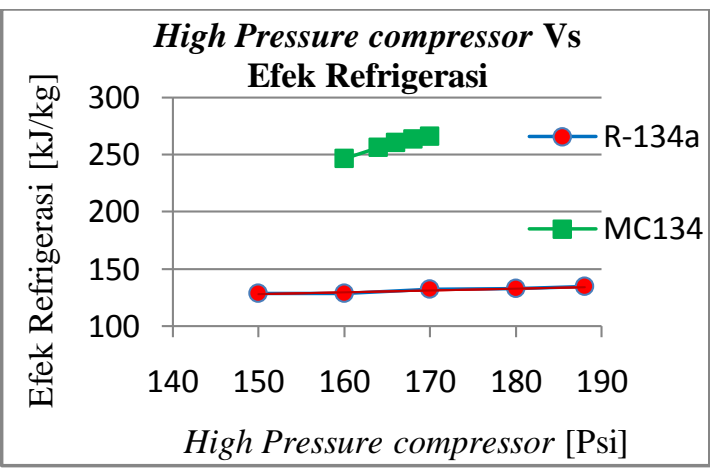

Gambar 2. Grafik Perbandingan High Pressure compressor terhadap Efek Refrigerasi

Gambar 2 merupakan grafik yang menunjukkan bahwa kenaikan high pressure compressor berbanding lurus juga dengan kenaikan efek refrigerasi pada evaporator baik menggunakan refrigeran R-134a maupun hidrokarbon.

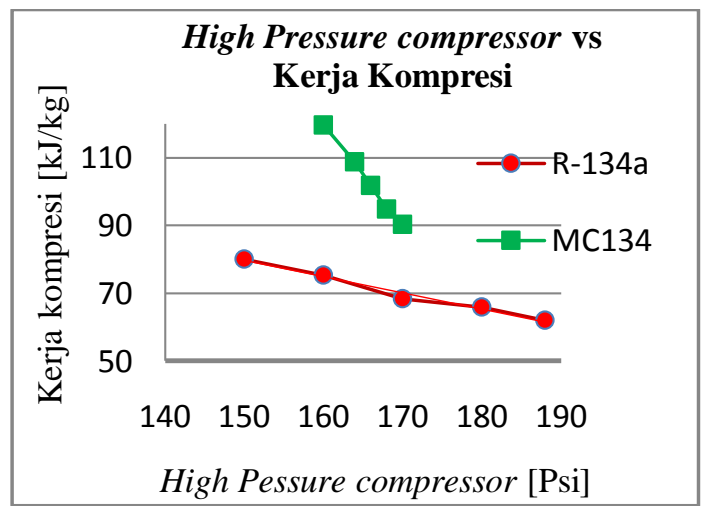

Gambar 3. Grafik perbandingan High Pressure compressor terhadap Kerja Kompresi

Gambar grafik di atas menunjukan bahwa kenaikan high pressure compressor pada kedua jenis refrigeran berbanding terbalik terhadap nilai kerja kompresi. Semakin tinggi nilai high pressure compressor maka semakin terjadi penurunan nilai kerja kompresi, sehingga kerja kompresor semakin ringan.

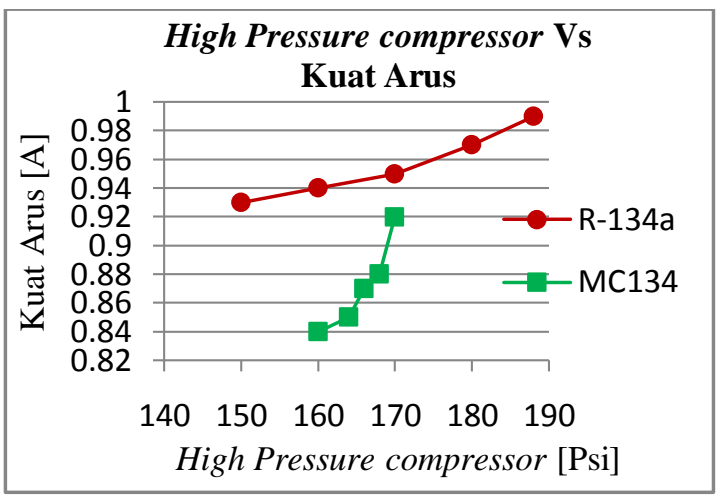

Gambar 4. Grafik perbandingan High Pressure compressor terhadap Kuat Arus

Berdasarkan gambar grafik di atas dapat di simpulkan bahwa kenaikan high pressure compressor setelah melewati kompresor pada kedua jenis refrigeran (R-134a dan hidrokarbon) akan terjadi kenaikan nilai kuat arus (konsumsi penggunaan energi listrik).

Dari keempat gambar grafik di atas (1, 2, 3 dan 4) menunjukan bahwa pemakaian refrigeran hidrokarbon MC-134 isian penuh terjadi kestabilan nilai high pressure kompresor antara 160 s/d 170 Psi. Sedangkan untuk pemakaian refrigeran $\mathrm{R}-134 \mathrm{a}$ terjadi perbedaan yang besar yaitu antara $150 \mathrm{~s} / \mathrm{d} 188$ Psi.

Pada pemakaian refrigeran hidrokarbon MC-134 besaran nilai kuat arus yaitu antara 0,84 s/d 0,92 Ampere (184,8 s/d 202,4 watt). Sedangkan pada pemakaian refrigeran R-134a sebesar 0,93 s/d 0,99 Ampere (204,6 s/d 217,8 watt).

\section{Kesimpulan}

Berdasarkan hasil data dan analisa pembahasan dari penelitian ini dapat disimpulkan sebagai berikut:

1. Pada pemakaian refrigeran hidrokarbon MC-134 isian penuh terjadi kestabilan nilai high pressure kompresor antara $160 \mathrm{~s} / \mathrm{d} 170$ Psi. Sedangkan untuk pemakaian refrigeran R-134 terjadi perbedaan yang besar yaitu antara $150 \mathrm{~s} / \mathrm{d} 188$ Psi.

2. High Pressure keluaran kompresor berpengaruh terhadap performansi di dalam sistem refrigerasi yang dapat dilihat dari besaran nilai COP (coeffisien of performance). 
3. Terjadi penghematan konsumsi energi listrik pada pemakaian refrigeran hidrokarbon MC-134 yang ditunjukkan oleh besaran nilai kuat arus yaitu antara 0,84 s/d 0,92 Ampere (184,8 s/d 202,4 watt) dibandingkan dengan pemakaian refrigeran R-134a sebesar 0,93 s/d 0,99 Ampere (204,6 s/d 217,8 watt).

\section{Ucapan Terima Kasih}

Terima kasih ditujukan kepada PT. Pertamina (Persero) Balikpapan yang telah memberikan bantuan refrigeran hidrokarbon merk Musicool (MC-134) untuk penelitian ini.

\section{Daftar Pustaka}

Arismunandar, W dan Saito, H, 2002, Penyegaran Udara, Cetakan ke-6, PT. Pradnya, Paramita, Jakarta.

Dincer, I., 2003, Refrigeration System and Application, Wiley, England.
Handoko K., 2004, Alat Kontrol Mesin

Pendingin, PT. Ichtiar Baru, Jakarta.

Herlianika, H, 2005, Eksperimen Dengan

Alat Peraga Refrigerasi Dasar, PT. Ardhika Widya Hutama, Bandung.

Moran J. Michael \& Shapiro, N, 2006, Howard, Fundamentals of Engineering Thermodinamics $5^{\text {th }}$ Edition. John Wiley \& Son Ltd. England.

Pasek, A.D., 2007, Retrofit Sistim Refrigerasi Dan Pengkondisian Udara Ramah Lingkungan, Pusat Pendidikan dan Pelatihan Kementerian Lingkungan Hidup, Jakarta.

Stocker, W.F., 1996, Refrigerasi dan Pengkondisian Udara, Erlangga, Jakarta.

Trott A.R. \& Welch T.C., 2000, Refrigeration \& Air-Conditioning Third Edition, Butterworth-Heinemann, Oxford. 